\title{
DEXAMPHETAMINE AND ALCOHOL EFFECTS IN SIMULATED DRIVING AND COGNITIVE TASK PERFORMANCE
}

\author{
Marieke Martens $^{1}$, Ries Simons ${ }^{1}$, \& Jan Ramaekers ${ }^{2}$ \\ ${ }^{1}$ TNO Human Factors, Soesterberg \\ ${ }^{2}$ University of Maastricht, Maastricht \\ The Netherlands \\ Email: marieke.martens@tno.nl
}

\begin{abstract}
Summary: This study assessed the effects of dexamphetamine with and without alcohol on simulated driving and cognitive tasks. 18 subjects participated in all 4 conditions: $10 \mathrm{mg}$ dexamphetamine and $0.8 \mathrm{~g} / \mathrm{kg}$ alcohol, $10 \mathrm{mg}$ dexamphetamine only, $0.8 \mathrm{~g} / \mathrm{kg}$ alcohol only, and a placebo control condition. A driving simulator was used to assess driving skills and risk taking on different road types. Cognitive performance was assessed using vigilance and divided attention tasks and subjects completed different rating scales. The main effects found were those of alcohol. This related to a larger standard deviation of lateral position, shorter accepted gap time and distance, higher average and maximum driving speeds and more violations of speed limits. A higher percentage of subjects in the dexamphetamine + alcohol condition did not stop for the red traffic lights, or collided with a vehicle. Performance of vigilance and divided attention tasks was impaired in the alcohol condition and impaired to a lesser degree in the dexamphetamine + alcohol condition. The conclusions of this study are that the main effect of impaired driving was found in the effect of $0.8 \mathrm{~g} / \mathrm{kg}$ alcohol dose at the control level and the maneuvering level. The amphetamine dose did not potentiate risk taking behaviour, but also did not overcome the negative effects of alcohol. The findings of the present study justify the conclusion that drivers using $0.8 \mathrm{~g} / \mathrm{kg}$ alcohol, or the combination of dexamphetamine with alcohol, pose a considerable traffic safety risk.
\end{abstract}

\section{OBJECTIVES}

The effects of alcohol on driving performance are well documented and impaired performance has been evidenced for doses as low as 0.3\%o (Weiler et al, 2000; Vermeeren et al, 2002; Veldstra et al, 2010; for a review see Moskowitz and Robinson, 1986). However, even though there is a considerable body of knowledge concerning the effects of amphetamines (under the population also called 'speed') on cognition and behaviour, there is hardly any research available on the effects of dexamphetamine on driving and literature is contradictory about general risk taking effects. Dexamphetamine is a psychostimulant hard drug and is used as a recreational stimulant, which may induce euphoria and alertness. A 'usual' recreational dose is between 5 and $40 \mathrm{mg}$. About 2\% of the Dutch adult population (18-64) indicates that they ever used amphetamines (National Drug Monitor - Yearly review 2007).

Some studies have reported decreases in impulsive behaviours following acute doses of 10 or 20 mg dexamphetamine (de Wit et al. 2002) and others have shown increases in impulsive behaviours (Hurst et al. 1967; Evenden and Ryan, 1996). Concerning cognitive tasks, the 
literature indicates that, at lower doses, dexamphetamine appears to improve performance (e.g. De Wit et al., 2002; Ward et al., 1997). However, Mills et al. (2001) found that $10 \mathrm{mg}$ dexamphetamine induces 'tunnel vision', producing a decrease in an individual's ability to gather information efficiently. Since in party circuits, dexamphetamine is frequently used in combination with higher doses of alcohol, it is interesting to not only study the effects of dexamphetamine, but also the effects of dexamphetamine and alcohol combined. On a theoretical basis, it was expected that dexamphetamine reduces sedation and impairment of vigilance caused by alcohol, but potentiates risk-taking behaviour and impaired judgement.

\section{METHODS}

\section{Subjects}

Eighteen recreational users (< once a week) of alcohol and amphetamine-like substances (including ecstasy) participated in the study. All subjects had at least two years of driving experience. All volunteers had a pre-study screening with a physical examination and an anamnesis (e.g. exclusion criteria were history of drug addiction, pregnancy, using medicines etc). The study was approved by the Medical Ethics Committee of the University Medical Center Utrecht. Subjects were recruited via a website with help of the Trimbos Institute.

\section{Design}

The double blind, placebo controlled study had a randomized cross-over repeated measures design. The conditions were: 1) 10mg dexamphetamine + alcohol-free drink (AMP+PLA) 2) 0.8 $\mathrm{g} / \mathrm{kg}$ alcohol + placebo for dexamphetamine (ALC+PLA) 3) $10 \mathrm{mg}$ dexamphetamine $+0.8 \mathrm{~g} / \mathrm{kg}$ alcohol (AMP+ALC) and 4) placebo for dexamphetamine + alcohol-free drink (PLA + PLA). Wash-out period between the study conditions was 7 days. In order to standardize circadian influences, each subject was assessed at the same time of day in each condition.

\section{Procedure and independent variables}

A week before the first trial, subjects were trained in the driving task in the simulator and the cognitive tasks. On each of the four trial days, subjects were screened for alcohol and drugs. All sessions took place in the afternoon/early evening. The effect of ethanol is felt very fast, however the Cmax of $10 \mathrm{mg}$ dexamphetamine (maximum concentration) is estimated to be $2.6 \pm 2.5 \mathrm{~h}$ after ingestion (De Wit et al., 2000). Because it was pursued that the Tmax (the amount of time that the drug is present at the maximum concentration) covers the 50 min simulated driving test, the best time for testing the driving capabilities was approximately two hours after ingestion of dexamphetamine. Time of ingestion of dexamphetamine was then defined as $\mathrm{T}=0$. The ethanol ingestion has been titrated to be $1 \%$ on $\mathrm{T}=120$ minutes according to the method described in De Wit et al (2000). Each trial day tests were performed at the following experimental times:

$\begin{array}{ll}\mathrm{T}=-10 & \text { baseline session for VigTrack vigilance task } \\ \mathrm{T}=0 & \text { orange juice }+10 \mathrm{mg} \text { dexamphetamine or placebo } \\ \mathrm{T}=41 & 0.2 \mathrm{~g} / \mathrm{kg} \text { ethanol in orange juice } \\ \mathrm{T}=73 & 0.2 \mathrm{~g} / \mathrm{kg} \text { ethanol in orange juice } \\ \mathrm{T}=105 & 0.4 \mathrm{~g} / \mathrm{kg} \text { ethanol in orange juice }\end{array}$




$\begin{array}{ll}\mathrm{T}=120-170 & \text { simulated driving test } \\ \mathrm{T}=180-200 & \text { cognitive tasks, rating scales } \\ \mathrm{T}=240-260 & \text { cognitive tasks, rating scales } \\ \mathrm{T}=300 & \text { end of study sessions }\end{array}$

Participants drove the TNO driving simulator, consisting of a BMW 316 car mock-up with original controls linked to a dedicated graphics computer. Participants had a $180^{\circ}$ screen, interactive traffic, sound and a hexapod moving base. All scenarios for the driving simulator were developed by the University of Groningen (Veldstra et al., 2010). The simulated drive had duration of about 50 minutes, with urban, rural, and highway driving with various traffic densities. Also, critical events were included at random locations.

Dependent variables. The driving performance measures were speed, lateral position, SDLP, headway, time to line crossing, time-to-collision, gap acceptance, car following behaviour, response to traffic lights and response to other vehicles taking the right of way and sudden traffic jams with strong braking.

Subjects also performed five lab tests: 1 ) the Critical Tracking Task (CTT) measuring the ability to control a displayed error signal in a $1^{\text {st }}$-order compensatory tracking task 2) Divided Attention Task (DAT), assessing the ability to divide attention between two tasks 3) the Psychomotor Vigilance Task (PVT), assessing the reaction time to a visual stimulus 4) the VigTrack, a dualtask measuring vigilance performance under the continuous load of a compensatory tracking task and 5) the Selective attention task from the usual field of view test (UFOV, a.o. Ball \& Owsley, 1992). Also, subjective measures were registered, such as the Profile of Mood States, the Rating Scale Mental Effort, the Driving Quality Scale, and the Karolinska Sleepiness Scale.

\section{RESULTS}

For analysing the data, analysis of variance was used. Due to the substantial amount of data and tests, we will only report some of the tests. Also, only significant results will be reported here.

Altogether there were two drop-outs (due to sickness and medical reasons). Data sets of 16 volunteers (4 female and 12 male) were available for analysis. Mean age of the subjects was 25.7 yr and on average, subjects held a driving license for 4.3 years and drove $5600 \mathrm{~km} / \mathrm{yr}$. Alcohol levels were measured in breath by the Dräger Alcotest 6510 (Lubeck) and transformed to BAC (Table 1).

Table 1. Blood alcohol concentrations (\%) and ranges ( ) measured at various points in time

\begin{tabular}{cccccc}
\hline & $\mathrm{T}=120$ & $\mathrm{~T}=170$ & $\mathrm{~T}=200$ & $\mathrm{~T}=240$ & $\mathrm{~T}=260$ \\
\hline AMP+ALC & 0.91 & 0.64 & 0.55 & 0.35 & 0.23 \\
& $(0.63-1.22)$ & $(0.47-0.77)$ & $(0.39-0.66)$ & $(0.22-0.58)$ & $(0.10-0.43)$ \\
ALC +PLA & 0.85 & 0.64 & 0.57 & 0.37 & 0.26 \\
& $(0.61-1.13)$ & $(0.46-0.77)$ & $(0.41-0.64)$ & $(0.18-0.51)$ & $(0.08-0.41)$ \\
\hline
\end{tabular}


PROCEEDINGS of the Sixth International Driving Symposium on Human Factors in Driver Assessment, Training and Vehicle Design

Table 2. Concentrations (ng/mL) and ranges ( ) of d-amphetamine in the conditions AMP and AMP+ALC

\begin{tabular}{lcc}
\hline $\mathrm{T}=115$ & Blood & Plasma \\
\hline AMP+ALC & $20.7(11.9-39.1)$ & $24.1(13.2-41.1)$ \\
AMP+PLA & $20.8(11.8-40.7)$ & $22.6(14.2-40.3)$ \\
\hline
\end{tabular}

\section{Driving performance}

SD of Lateral Position. The SDLP was assessed during monotonous driving (not much traffic, no curves) on an $80 \mathrm{~km} / \mathrm{h}$ road (5.9 km long) and on a motorway (speed limit $100 \mathrm{~km} / \mathrm{h}, 4.8$ kilometers long). Mean SDLP was 32\% (4.9 cm) higher in the alcohol condition (ALC) than in the placebo condition (PLA). The differences between the alcohol and the placebo condition were significant at $80 \mathrm{~km} / \mathrm{h}\left(\mathrm{F}_{1,12}=7.12 ; \mathrm{p}<0.02\right)$ as well as at $100 \mathrm{~km} / \mathrm{h}\left(\mathrm{F}_{1,12}=6.49 ; \mathrm{p}<0.03\right)$. Results are presented in table 3.

Table 3. SDLP (cm) with SD for monotonous driving

\begin{tabular}{lcccc}
\hline & AMP+PLA & AMP+ALC & ALC+PLA & PLA+PLA \\
\hline SDLP $80 \mathrm{~km} / \mathrm{h}$ & $17.8 \pm 5.6$ & $17.2 \pm 5.3$ & $20.3 \pm 8.1$ & $15.4 \pm 2.7$ \\
SDLP $100 \mathrm{~km} / \mathrm{h}$ & $18.8 \pm 7.9$ & $17.7 \pm 8.2$ & $20.1 \pm 6.8$ & $15.2 \pm 4.1$ \\
\hline
\end{tabular}

Speed. On a $50 \mathrm{~km} / \mathrm{h}$ road, an effect was found of treatment on average speed $\left(\mathrm{F}_{3,36}=1.92 ; \mathrm{p}<.07\right.$, trend), SD of speed $\left(\mathrm{F}_{3,36}=3.02 ; \mathrm{p}<.04\right)$ and maximum speed $\left(\mathrm{F}_{3,36}=3.86 ; \mathrm{p}<.02\right)$. Subjects with ALC had a higher average speed than those using AMP or PLA $(\mathrm{p}<.05)$, a higher SD of speed than in the PLA condition $(p<.05)$, and a higher maximum speed than in the AMP and PLA conditions. A treatment effect was found for the SD of speed when driving on an $80 \mathrm{~km} / \mathrm{h}$ road $\left(\mathrm{F}_{3,39}=4.05 ; \mathrm{p}<.01\right)$. Subjects with AMP+ALC showed a higher $\mathrm{SD}_{\text {speed }}$ than in the other treatments $(p<.05)$. When driving on the motorway with a speed limit of $100 \mathrm{~km} / \mathrm{h}$ subjects with AMP+ALC treatment showed higher S.D. of speed than in other treatment conditions $\left(\mathrm{F}_{3,39}=3.47 ; \mathrm{p}<.003\right)$.

Gap acceptance. There were two city junction gap acceptance challenges with traffic coming from the left and right side (gap LR) and upcoming traffic at a Y-junction (gap Y). No traffic lights were present and road markings and a traffic sign indicated that the other traffic had the right of way.

In both gap acceptance challenges a significant treatment effect was found on accepted gap time $\left(\mathrm{F}_{3,42}=5.13 ; \mathrm{p}<.004\right.$ and $\mathrm{F}_{3,42}=3.88 ; \mathrm{p}<.02$ respectively) and accepted gap distance $\left(\mathrm{F}_{3,42}=3.87\right.$; $\mathrm{p}<.02$ and $\mathrm{F}_{3,42}=4.41 ; \mathrm{p}<.009$ ). Compared to the other treatments, accepted gap time and distance were significantly shorter when subjects had used ALC. However, no significant difference was found between AMP+ALC en ACL concerning gap distance (see Figure 1 and Figure 2).

Traffic lights. Some of the traffic light scenarios were set in order to induce a real dilemma for the driver, where drivers suddenly had to stop for the red light. Drivers in the AMP+ALC and ALC conditions passed the red light in $64 \%$ and $59 \%$ of the cases, while in the AMP and PLA conditions drivers did not stop in $30 \%$ of the cases (chi-square $=10.8496, \mathrm{df}=3, \mathrm{p}<0.02$ ). 
Accidents and dangerous actions. When encountering a traffic jam at the highway, traversing unsignalised crossroads, or filtering into the traffic some participants collided with a vehicle. Compared with placebo, significantly more accidents were observed in the ALC and the $\mathrm{AMP}+\mathrm{ALC}$ conditions $\left(\mathrm{F}_{1,13}=6.06 ; \mathrm{p}<0.03\right)$. In total there were 18 collisions, with 1 collision for AMP, 6 for AMP + ALC, 8 for ALC and 3 for the control condition. Even though the number of 18 collisions seems rather high, it must be noted that the experiment was specifically designed in order to be able to include very critical driving situations, such as monotonous driving, critical gap acceptance situations, sudden manoeuvres of other cars and hard braking in case of traffic queues.

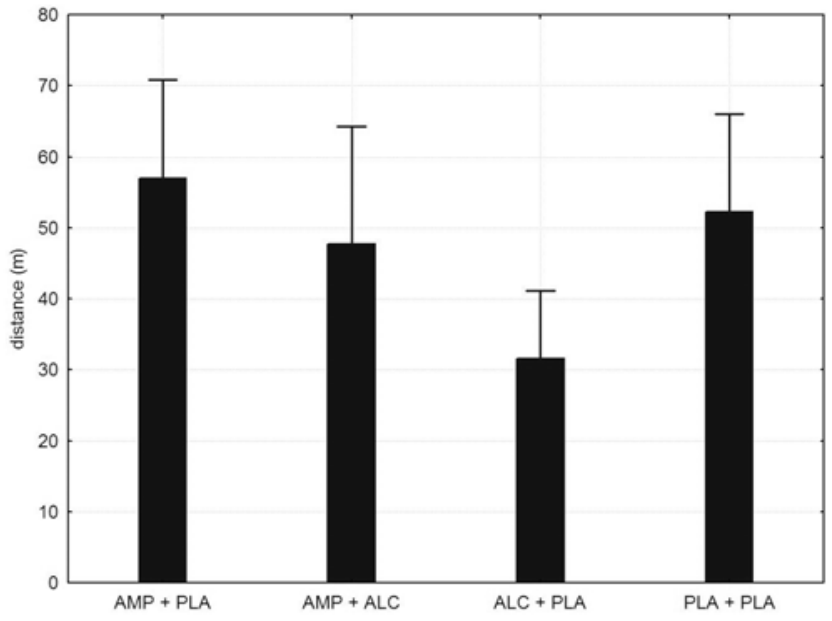

Figure 1. Gap acceptance distance (m); Whiskers denote 0.95 confidence intervals

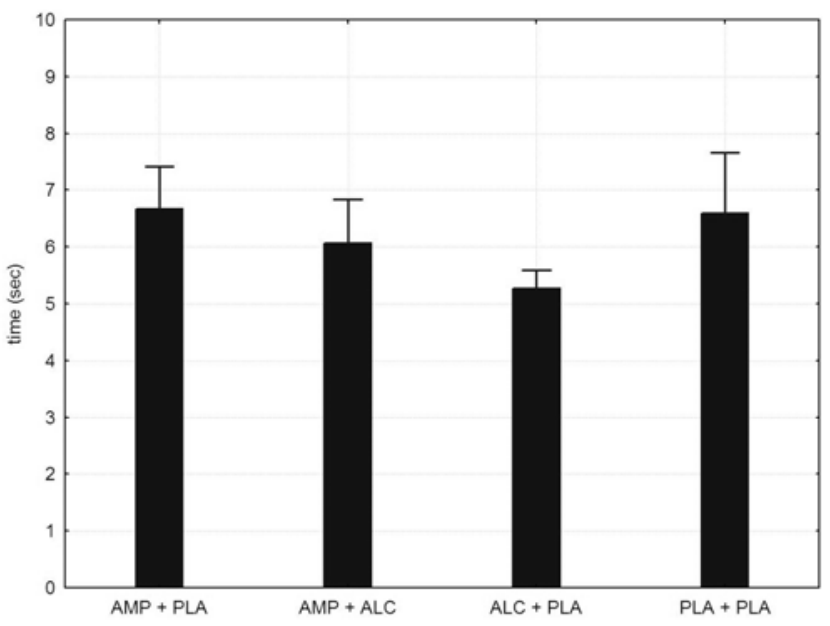

Figure 2. Gap acceptance time (s); Whiskers denote 0.95 confidence intervals

Other dependent driving variables. No significant differences could be demonstrated between the treatment conditions concerning:

- The average and minimum TLC, or the number of line crossings

- for the car following scenarios, no significant differences could be demonstrated

- In the intersection give-way situation, no difference was found between the treatments

- In case of a car suddenly pulling out from a parking, no differences were found in response

Cognitive tasks. The first test sessions of the cognitive tasks were performed 10 minutes after completion of the simulated driving task $(\mathrm{T}=180)$ and a second session was performed one hour later $(\mathrm{T}=240)$. The first cognitive test session was performed with mean BACs between 0.64 and $0.55 \%$, while mean BACs during the second session were between 0.37 and $0.23 \%$.

The critical tracking frequency showed no significant differences between the treatments. Performance on the DAT was significantly impaired for subjects using ALC. Compared to the other conditions, they showed a larger tracking error $\left(\mathrm{F}_{3,39}=5.15 ; \mathrm{p}<.004\right)$, higher reaction time $\left(\mathrm{F}_{3,39}=4.04 ; \mathrm{p}<.02\right)$, higher number of missed targets $\left(\mathrm{F}_{3,39}=5.05 ; \mathrm{p}<.005\right)$, a lower number of hits $\left(F_{3,39}=5.05 ; \mathrm{p}<.005\right)$, higher number of control losses $\left(\mathrm{F}_{3,39}=6.39 ; \mathrm{p}<.001\right)$, and more false alarms $\left(\mathrm{F}_{3,39}=4.04 ; \mathrm{p}<.01\right)$. The number of false alarms was higher when subjects used AMP+ALC compared to AMP ( $<<.05)$. The number of lapses of attention on the Psychomotor Vigilance task was highest when subjects had used ALC (trend: $\mathrm{F}_{3,42}=2.75 ; \mathrm{p}<.06$ ). The ALC treatment showed 
significantly more lapses than AMP treatment $(\mathrm{p}<.05)$. There were no significant differences between treatments with regard to mean reaction time. Subjects using ALC showed significantly impaired vigilance performance on the Vigtrack compared to the other conditions. This was signified by a larger tracking error $\left(\mathrm{F}_{3,45}=5.01 ; \mathrm{p}<.005\right)$, longer reaction times $\left(\mathrm{F}_{3,45}=8.38\right.$; $\mathrm{p}<.0002$ ), and a higher percentage of omissions (trend: $\mathrm{F}_{3,45}=2.55 ; \mathrm{p}<.07$ ). Tracking performance of subjects using ALC showed 50\% impairment compared to baseline values. No significant differences between treatments were found on the divided attention part of the UFOV task.

Subjective rating scales. There were treatment effects on the Karolinska sleepiness scores $\left(\mathrm{F}_{3,45}=6.82 ; \mathrm{p}<.0007\right)$ Subjects using AMP or AMP+ALC were less sleepy than subjects using placebo or alcohol alone ( $\mathrm{p}<.01$ for both dexamphetamine treatments). There was no significant difference in treatment on the estimated mental effort during driving. Subjects using AMP showed higher subjectively estimated driving quality than those who used ALC $(\mathrm{p}<.05)$. Treatment effects were found indicating that subject using AMP felt less fatigued, more energetic, more cheerful, less depressed, and more clear-headed than when they had used ALC or PLA (all $\mathrm{p}<.05)$.

\section{CONCLUSIONS}

Findings of the present study support existing scientific consensus that $0.8 \mathrm{~g} / \mathrm{kg}$ alcohol negatively affects driving performance and traffic safety. Alcohol affected driving skills at control (lateral position and speed), and manoeuvring levels (gap acceptance, reaction to traffic light, violations).

No significant indication was found that the addition of $10 \mathrm{mg}$ dexamphetamine to $0.8 \mathrm{~g} / \mathrm{kg}$ alcohol always increased risky traffic behaviour, associated with the use of $0.8 \mathrm{~g} / \mathrm{kg}$ alcohol. This may be explained by the use of a relative low dose $(10 \mathrm{mg})$ of dexamphetamine in the present study. Such dose may have favoured the reduction of sedation and disinhibition caused by alcohol, while the dose might have been too low to cause impaired judgment and stimulation of risk taking behaviour. However, negative effects of the combination of dexamphetamine and alcohol were found on the variance in speed (larger standard deviation in speed, which is associated with unsafe behaviour), red light running and a higher number of false alarms on the cognitive task.

However, combination of dexamphetamine and $0.8 \mathrm{~g} / \mathrm{kg}$ alcohol also does not seem to mitigate the effects of alcohol. Although a mitigating effect of dexamphetamine was found in addition to alcohol (compared to alcohol alone) on the amount of swerving within a lane (standard deviation of lateral position), still many negative effects of the combination of dexamphetamine and alcohol were found. Impaired effects were found on cognitive tasks and on lateral position, speed, and gap acceptance, as well as on highly dangerous driving acts, such as red-light running and the number of accidents were much more frequently observed in the alcohol and alcohol + dexamphetamine conditions than in the other conditions.

The findings of the present study justify the conclusion that individuals using alcohol, or the combination of dexamphetamine with alcohol, should not be allowed to participate in traffic. One of the limitations of this study is that a specific amount of dexamphetamine and alcohol was 
chosen, whereas it would also be interesting from a practical point of view what the most common doses would be in the recreational scene and after an entire evening of partying. However, in this study, the medical ethical committee did not allow us to use a higher concentration of dexamphetamine.

\section{ACKNOWLEDGEMENTS}

This study was part of the $6^{\text {th }}$ FP European Integrated project DRUID. We are greatly indebted to Janet Veldstra and Karel Brookhuis, University of Groningen, who made their driving scenario and their alcohol calibration study available for us and patiently answered all of our questions.

\section{REFERENCES}

Ball, K. \& Owsley, C. (1992). The useful field of view test: a new technique for evaluating agerelated declines in visual function. Journ of the Am Optom Ass, 63, 71-79.

De Wit, H., Crean, J. \& Richards, J.B. (2000). Effects of d-amphetamine and ethanol on a measure of behavioral inhibition in humans. Behavioral Neuroscience, 114(4), 830-837.

De Wit, H., Enggasser, J.L. \& Richards, J.B. (2002). Acute administration of d-aphetamine decreases impulsivity in healthy volunteers. Neuropsychopharmacology, 27(5), 813-825.

Evenden, J.I. \& Ryan, C.N. (1996). The pharmacology of impulsive behaviours in rats: the effects of drugs on response choice with varying delays of reinforcement. Psychopharmacology, 128, 161170.

Hurst, P.M., Weidner, M.F. \& Radlow, R. (1967). The effects of amphetamines upon judgement and decisions. Psychopharmacologia; 1(5), 397-404.

Mills, K.C., Spruill S.E., Kanne, R.W., Parkman, K.M. \& Zhang, Y. (2001). The influence of stimulants, sedatives, and fatigue on tunnel vision: risk factors for driving and piloting. Human Factors; 43(2), 310-327.

Moskowitz, H. \& Robinson, C. (1986). Driving-related skills impairment at low alcohol levels. In: P.C. Noordzij, R. Roszbach (Eds) Alcohol, drugs and traffic safety -T86. Excerpta Medica International Congress Series 721. Excerpta Medica, Amsterdam.

Veldstra, J.L., Brookhuis, K.A. \& de Waard, D. (2010). Dose related effects of alcohol on simulated driving performance: a calibration study. Report Department of Traffic and Environmental Psychology of the University of Groningen, the Netherlands.

Vermeeren, A., Ramaekers, J.G. \& O’Hanlon, J.F. (2002). Effects of emedastine and cetirizine, alone and with alcohol, on actual driving of males and females. Psychopharmac, 16(1), 64.

Ward, A.S., Kelly, T.H., Foltin, R.W. \& Fischman, M.W. (1997). Effects of d-amphetamine on task performance and social behavior of humans in a residential laboratory. Exp Clin Psychopharmac, 5(2), 130-136.

Weiler, J.M., Bloomfield, J.R., Woodworth, G.W., Grant, A.R., Layton, T.A., Brown, T.L., McKenzie, D.R., Baker, T.W. \& Watson, G.S. (2000). Effects of Fexofenadine, Diphenhydramine, and Alcohol on Driving Performance. A randomized, Placebo-Controlled Trial in the Iowa Driving Simulator. Annual Intern Med, 132, 354-363.

Wit, H., de, Crean, J., Richards, J.B. (2000). Effects of d-amphetamine and ethanol on a measure of behavioral inhibition in humans. Behavioral Neuroscience, 114(4), 830-837. 